\title{
RESONANDO EN EL MAPA DE LA DIÁSPORA AFRICANA. PERFORMANCE DEL TUMBE CARNAVAL AFROARIQUEÑO: LO AFECTIVO EN LA MOVILIZACIÓN SOCIAL
}

\author{
Resounding the map of the African Diaspora. \\ Afro-Arican "Tumbe Carnaval" performance: \\ the affective in social mobilization
}

\author{
Daniel Domingo Gómez \\ Universidad de Santiago de Chile, Chile
}

\begin{abstract}
Resumen: El 16 de abril de 2019, el Estado chileno promulgó la ley núm. 21151, que otorga el reconocimiento legal al pueblo tribal afrodescendiente. Este logro fue posible por el movimiento social que encabezaron las organizaciones afroariqueñas desde inicios del siglo XXI. En este trabajo se examinan las articulaciones que se producen entre la política, la memoria y la performance del tumbe carnaval, un género de música-danza afroariqueño que, por las posibilidades que ofrece el multiculturalismo, puso en tensión la narrativa que negaba su presencia en el Chile republicano.
\end{abstract}

Palabras clave: afrochilenos, performance afro, política, memoria, música, multiculturalismo.

Abstract: On April 16th, 2019, the Chilean State enacted its Law 21.151, which grants legal recognition to the Afro-descendant tribal people. This achievement was possible due to the social movement, led by its own organizations, which started in the 21st century. This work examines the connections between politics, memory and the Tumbe Carnaval, an Afro-Chilean musical-dance performance, which, due to the possibilities offered by multiculturalism, has raised awareness of the narrative that denied its presence in Republican Chile.

Keywords: Afro-Chilean, afro performance, politics, memory, music, multiculturalism.

1. Esta investigación es parte de la tesis que el autor realiza en el Doctorado en Estudios Americanos de la Universidad de Santiago de Chile y cuenta con el apoyo de ANID - Subdirección de Capital Humano / Doctorado Nacional / 2021-21210937. Mi agradecimiento al pueblo afroariqueño y a los y las integrantes de las comparsas, porque este trabajo no habría sido posible sin ellos. 


\section{Introducción}

En diciembre del año 2000, se produjo un punto de inflexión dentro del movimiento afroamericano cuando un pequeño grupo de afrochilenos irrumpió en la Conferencia Regional de las Américas, celebrada en Santiago de Chile, con la intención de reivindicar tanto su existencia como su aporte en la construcción de la nación republicana. Con este hito histórico se presentaron en la escena nacional e internacional, ampliando el mapa de la diáspora africana.

De este modo, se inició un proceso de politización de la identidad cultural afrochilena, cuyo foco principal emerge en Arica, ciudad fronteriza situada en el extremo norte del país. Este esfuerzo organizativo buscaba denunciar su exclusión por parte de la narrativa canónica construida por los representantes del Estado, quienes desde el siglo XIX venían fomentando un imaginario en el cual la población afrodescendiente quedaba borrada de la geografía, la historia y la identidad del Chile republicano (Domingo, 2021b).

Casi dos décadas después, el 12 de junio de 2019, una delegación compuesta por integrantes de diversas organizaciones políticas y socioculturales del pueblo afrodescendiente volvió a la zona central del país, pues fueron invitados al Salón de Honor del Congreso Nacional en Valparaíso. El motivo fue un acto de celebración debido a la promulgación de la ley núm. 21151, la cual trajo consigo el reconocimiento legal del pueblo tribal afrodescendiente chileno. ${ }^{2}$

Aparte de lo trascendental del momento, entre los dos eventos mencionados se produjeron notables diferencias. En el año 2000 había un pequeño grupo de activistas, mientras que en 2019 la identificación política había movilizado a un gran número de personas. Además, en esta última ocasión, exhibieron un género de música-danza llamado tumbe carnaval, con un ritmo y una vestimenta que aludían a una africanización estética (Daponte, 2019). Esta manifestación cultural fue rescatada de la memoria oral de los abuelos afrodescendientes, y fue resignificada en el contexto local y de la diáspora africana (León, 2017; Wolf, 2019).

El 13 de junio de 2019, un día después del segundo evento, los transeúntes que recorrían las calles peatonales del centro de Santiago pudieron escuchar una serie de cánticos («Esta es la tierra de los negros, donde suena mi tumbe afroariqueño»), ${ }^{3}$ acompañados por el resonar de su instrumentación (figura 1). Finalmente, bajo una leve lluvia se bailó y se tocó tumbe en la plaza Constitución, junto al frontis del Palacio de La Moneda.

2. La condición de «pueblo tribal» viene reconocida por el derecho internacional de los derechos humanos, como en el Convenio 169 de la Organización Internacional del Trabajo. En su artículo 1.1 define los pueblos tribales como los grupos "cuyas condiciones sociales, culturales y económicas les [distinguen] de otros sectores de la colectividad nacional, y que [están] regidos total o parcialmente por sus propias costumbres o tradiciones o por una legislación especial» (Guerra y Büchner, 2019: 76).

3. Parte de los cánticos que realizaron ese día, anotados por el autor. 
Figura 1. Pueblo afroariqueño en el frontis de La Moneda.

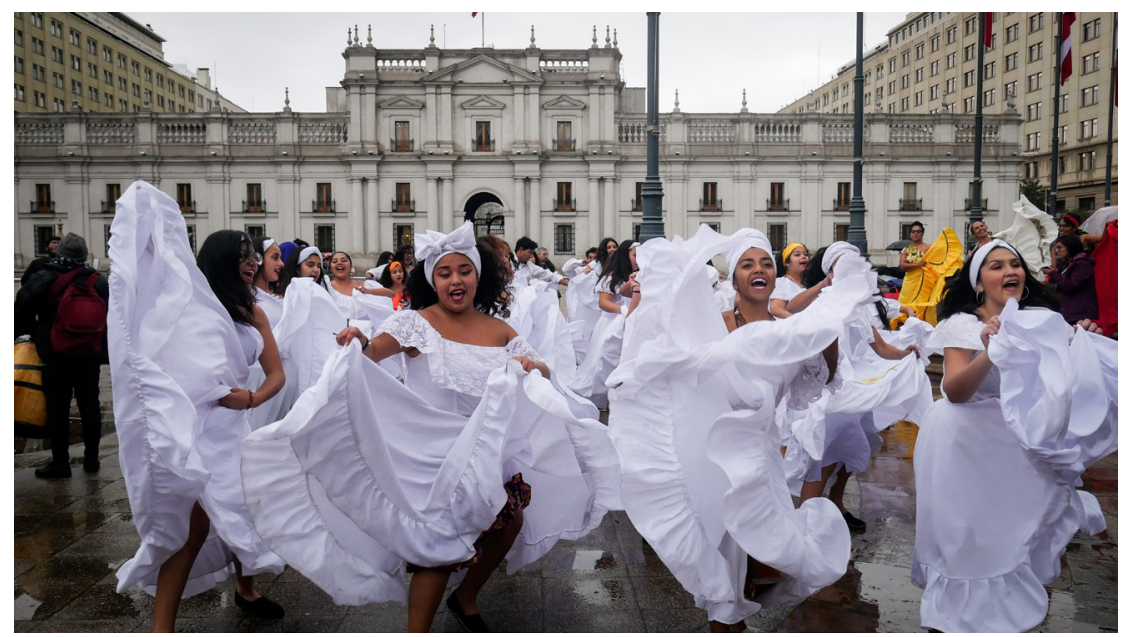

Fuente: Imagen de Daniel Miranda.

Dado ese contexto, el propósito de este trabajo es examinar la relevancia que tiene la performance del tumbe carnaval dentro del movimiento etnopolítico afrochileno, puesto que se trata de un fenómeno que, sumado a las acciones llevadas a cabo por las organizaciones, ha sido utilizado como una estrategia de reivindicación y visibilización político-cultural. Esto se debe a que sus cultores han aprovechado la estructura de oportunidades que proporciona el multiculturalismo (Frigerio y Lamborghini, 2011).

El interés principal es relacionar la articulación que se produce entre los trabajos de memoria (Jelin, 2012) y la performance del tumbe carnaval movilizado por el pueblo afroariqueño, en un contexto local y transnacional, para lograr sus demandas de reconocimiento y así construir una «ciudadanía basada en la diferencia y el pluralismo cultural» (Guerra y Büchner, 2019: 67).

Para ello, se presenta un trabajo que forma parte de una investigación que se inició en un Magíster de Musicología Latinoamericana, pero que todavía sigue en curso a través de un programa de doctorado. Metodológicamente tiene un enfoque cualitativo interdisciplinario, con un diseño etnográfico que articula distintas áreas de conocimiento (etnomusicología, política, estudios de performance sonoros y culturales). Se contrasta, a su vez, con abordajes previos dedicados a la afrodescendencia en Chile y con otros estudios afrolatinoamericanos.

La producción académica reciente ha situado al tumbe carnaval como parte del «renacimiento cultural e identitario» del pueblo afroariqueño (Ahumada, 2015; Espinosa, 2015; León, 2017; Mora, 2011) o como la expresión en que se produce su identificación con el movimiento de la diáspora (Daponte, 2019; Wolf, 2019). No obstante, y por eso mismo, queremos enfatizar su dimensión política.

Con este fin, en primer lugar, abordamos el contexto específico que se vivió en el territorio de Arica y sus valles, pues se produjo un período traumático rela- 
cionado con la guerra del Pacífico (1879-1883) y con el posterior proceso de chilenización (Alarcón, Araya y Chávez, eds., 2017; Artal, 2012). A continuación, situamos el panorama social y político producido durante la década de 1990, que hizo reaparecer estas memorias relegadas, para así abarcar la resignificación y tradicionalización ${ }^{4}$ del tumbe carnaval afroariqueño. Posteriormente, posicionamos el cuerpo, el sonido y la memoria como locus de enunciación político que son claves a la hora de generar prácticas emancipatorias que crean comunidad. Por último, destacamos su relevancia por incidir en el escenario de la protesta social, cuando se demanda por el reconocimiento y la promoción social.

\section{Imponiendo los límites de la nación. La chilenización del extremo norte}

Arica es una ciudad ubicada en la frontera septentrional de Chile, y su situación en la costa pacífica la convirtió, desde época colonial, en un enclave estratégico administrado por el Virreinato del Perú. Su importancia se debía a que su puerto «articulaba las vías que conectaban con el mineral de Potosí» (Díaz, Briones y Sánchez, 2019: 31-32). Al mismo tiempo, a pocos kilómetros tierra adentro hacia el altiplano, se encuentra el fecundo valle de Azapa, lugar donde los esclavizados fueron llevados para trabajar en las haciendas cultivando algodón, aceitunas y caña de azúcar.

La población afrodescendiente en este territorio fue de gran relevancia. Los datos censales muestran que, en el año 1871, de 7.835 personas, 1.549 fueron registradas como negras y representaban el $19 \%$ de toda la población. ${ }^{5}$ De este último, el $60 \%$ se ubicaba en la ciudad de Arica, mientras que el $40 \%$ restante residía en los valles, principalmente en Azapa, donde concentraban el 66\% de la población de la zona (Díaz, Muñoz y Lanas, 2019: 246-261).

Tras la proclamación de las independencias, el territorio fue administrado por la República de Perú; no obstante, a fines del siglo XIX se produjo la guerra del Pacífico, un conflicto armado que enfrentó a Chile contra Perú y Bolivia. La victoria de Chile quedó sellada bajo la firma del Tratado de Ancón en octubre de 1883, acuerdo de paz que entregó a la soberanía chilena el Departamento de Tarapacá y las provincias de Tacna y Arica. Estas últimas, sin embargo, disponían de diez años para decidir su futuro, pues se debía organizar un plebiscito para determinar finalmente bajo qué régimen quedaban, el peruano o el chileno. La consulta nunca se llevó a cabo, y en 1929 Tacna fue devuelta a Perú y Arica quedó en territorio chileno (Álvez e Irarrázaval, 2000).

4. Se sigue el concepto abordado por Frigerio y Lamborghini (2011) para el caso de la performance del candombe afroargentino, donde se produjo un proceso de tradicionalización consciente por apelar a prácticas y formas estéticas pasadas que son recontextualizadas en el presente.

5. Tal como lo señaló dicho estudio, las categorías clasificatorias que se usaron en el censo de 1871 fueron «blancos», «mestizos», «indios» $y$ «negros». Esto hace suponer que parte de la población considerada como mestiza tenía un origen afrodescendiente, por lo que su número sería todavía más alto. 
Bajo este contexto, desde finales del siglo XIX, Chile implementó una política para borrar cualquier elemento ajeno al ideal establecido de nación, principalmente a través del fortalecimiento del sistema educativo, de la llegada y el control ejercido por la iglesia castrense y de la imposición del servicio militar. Así se debía crear una nueva conciencia nacional.

Además, para consolidar el territorio, el Estado activó una necropolítica sobre las poblaciones afrodescendientes, esto es, se adjudicó el derecho de matar a la ciudadanía como un mecanismo de poder para imponer su soberanía (Mbembe, 2011). «El negro», considerado peruano, fue marcado y violentado, por lo que muchas familias se vieron obligadas a cruzar la frontera y a asentarse en territorio peruano. Otras, sin embargo, quedaron divididas, con lo que se provocó también una desestructuración familiar (Alarcón, Araya y Chávez, 2017: 8).

Por otra parte, quienes permanecieron en suelo chileno fueron coaccionados para que iniciaran procesos de blanqueamiento. Por tanto, el afroariqueño fue sujeto a un proceso de marcación corporal impuesto y, como consecuencia, se perfiló sus experiencias y el tipo de relaciones que debían establecerse tanto consigo mismo como con otros cuerpos (Bulo y Oto, 2015).

Desde esta perspectiva, el afroazapeño Cristian Báez, presidente de la Organización Lumbanga, define el período de la chilenización como otro momento donde se produjo un "genocidio en contra de nuestra cultura» (Báez, 2012: 71). Por esta razón, dejaron de mantenerse, por ejemplo, la práctica de jugar al carnaval o la devoción a san Martín de Porres, ${ }^{6}$ debido al sistema de control y vigilancia, que llevó a la pérdida de una parte de su herencia cultural.

Añadiendo un eco auditivo, las prácticas de escucha fueron condicionadas por las experiencias vividas y por el poder, donde el paisaje sonoro establecido como chileno configuró el nuevo territorio audible. Esto fue transversal y afectó en todos los ámbitos, e incluso hizo que se excluyeran del habla aquellas palabras que «sonaban peruanas", como «bemba» ('boca'), "chamba» ('trabajo') o «tambembe» ('trasero'), entre otras, y cuya etimología revela un origen africano, pues «más allá de una peruanidad había un origen ancestral que es africano»? En definitiva, el espacio público monopolizado por el aparataje nacionalizador relegó las memorias y tradiciones no aceptadas al ámbito privado, forzando así a un olvido social. ${ }^{8}$

La presidenta de la ONG Oro Negro, Marta Salgado, comenta que estas experiencias y discursos se instalaron en el tiempo, tanto que en la actualidad estas representaciones siguen articulando los esquemas mentales de parte de la población.

6. San Martín de Porres (Lima, 1579-1639), religioso peruano de la Orden de Predicadores (dominicos), quien fue el primer santo mulato del continente americano.

7. Entrevista realizada por el autor a Cristian Báez el 19 de junio de 2020.

8. El olvido social es definido como «imposibilidad de evocar o expresar acontecimientos significativos que en algún momento ocuparon un sitio en la vida del grupo, colectividad o sociedad, y cuya comunicación se ve obstruida o prohibida por entidades supragrupales como el poder» (Mendoza, 2007: 130). 
Una señora que murió tenía en su casa puras muñecas rubias porque ella quería haber sido rubia. ¿Por qué? porque sufrió discriminación con que era negra y que eso era malo y feo, po'. Entonces lo creían. Muchas no hablaban de que eran de familias negras. Incluso hoy día, puedes hablar con una familia y te va a decir: «la señora Marta Salgado hace un trabajo con los negros, pero nosotros no somos negros». Y "estay» mirándola que es negra. $Y$ son así porque no se quieren reconocer, todavía persiste ese estigma y ese miedo que se le metió a la cabeza a la gente [de] que ser persona negra era malo. $Y$ hay personas negras malas y buenas, ¡como en todos los pueblos! ${ }^{9}$

De este modo, las prácticas de exclusión, así como el racismo y la discriminación, que partían desde las instituciones tanto hacia colectividades como hacia individuos, tienen consecuencias directas en la vida social, ya que el rechazo puede ser interiorizado y orientado hacia sí mismo y generar en las personas sentimientos de inferioridad y endorracismo (Restrepo, 2012).

No obstante, eso no significa que este fenómeno ocurriera de forma generalizada. De hecho, a través de la constitución de sociedades religiosas de bailes de morenos, de colectivos de Cruces de Mayo e incluso mediante juntas vecinales o clubes deportivos, se conservaron y proyectaron elementos culturales y sociales, por lo que debe analizarse también en términos políticos.

Delante de una fiesta patronal, o de colectividades de Cruces de Mayo, que algunas tienen hasta 150 años, no sólo se tiene que ver la parte de la cultura, estábamos resistiendo como colectivo, eso es político. Hay una lucha desde tiempos de la colonia hasta día de hoy que siempre ha sido constante. ${ }^{10}$

Con todo, vemos que este período les obligó a sufrir un proceso de despojo y destierro, físico, territorial y cultural. La población local, de origen peruano, debía adoptar la chilenidad como nueva forma de vida. Sus memorias, asimismo, fueron intervenidas, y su piel quedó marcada negativamente «por una determinada distribución de la mirada, la voz y el tocar» como una "ontología de lo inexistente» (Bulo y Oto, 2015: 14).

\section{Las resistencias de la memoria. El movimiento etnopolítico afroariqueño}

En relación con lo anterior, abordamos la condición política del cuerpo/sonido como un elemento indispensable que ejerce su derecho de aparición en la esfera pública e instala demandas de justicia social. Para ello, debemos considerar que tanto las relaciones de poder como los procesos de racialización son históricos, y por lo tanto van redefiniéndose según los ciclos de la política racial global/local, hecho que produce que estén en una constante transformación (Parody, 2019).

9. Entrevista realizada por el autor a Marta Salgado el 4 de marzo de 2019.

10. Entrevista realizada por el autor a Cristian Báez el 19 de junio de 2020. 
Jelin defiende que las memorias silenciadas por regímenes represivos pueden reaparecer «a partir de cambios en los marcos culturales y sociales que impulsan a revisar y dar nuevo sentido a huellas y restos» (Jelin, 2012: 62). Es decir, bajo nuevas coyunturas políticas, más democráticas y abiertas, surgen aquellas memorias reprimidas que comienzan a reclamar reparación y justicia.

En Chile estos cambios se produjeron, en parte, por los movimientos de reivindicación de derechos de los pueblos indígenas, en un momento en el que el Estado avanzaba hacia un reconocimiento oficial de la diferencia, dentro del marco del multiculturalismo (Duconge y Lube, 2014; Espinosa, 2015). En 1990 se creó la Comisión Especial de Pueblos Indígenas, la cual trazó los planteamientos que debían guiar la nueva institucionalidad. Y este movimiento culminó con tres hitos: la aprobación de la llamada ley indígena (Ley núm. 19253, de 5 de octubre de 1993); la creación de la Corporación Nacional de Desarrollo Indígena, en 1994; y la incorporación de su autoidentificación en los censos nacionales. Además, estos pueblos también fueron favorecidos por un contexto político global en el cual la afrodescendencia comenzó a tomar relevancia y pudieron generarse movilizaciones sociales entre activistas afrodescendientes de diversos países y actores institucionales trasnacionales. Asimismo, se contó con el apoyo de instituciones multilaterales de financiamiento, como el Banco Mundial, la Comisión Económica para América Latina y el Caribe y el Banco Interamericano de Desarrollo, «lo cual originó dinámicas de coordinación y acción política» (Agudelo, citado en Echeverri-Pineda, 2020: 147).

Fue necesario este momento para que, a comienzos del siglo XXI, se iniciase un proceso organizativo afroariqueño que emergió progresivamente como sujeto político, reivindicó públicamente su existencia y demandó acciones para su promoción social. En diciembre del año 2000 , Sonia Salgado, afroariqueña y alcaldesa entonces de la comuna de Camarones, fue invitada a asistir a la Preconferencia Regional de Ciudadanía para las Américas, el Caribe y los Derechos Humanos que se iba a celebrar en Santiago. Este fue un evento internacional preparatorio para la Conferencia de Durban que se realizaría en el 2001 en Sudáfrica (Echeverri-Pineda, 2020; León, 2017).

Es durante la llamada Conferencia de Santiago cuando reaparece en el mapa de la diáspora africana la existencia de los afrochilenos, en el momento en que las hermanas Sonia y Marta Salgado se levantaron ante la mirada del entonces presidente de la República, Ricardo Lagos, y una gran cantidad de asistentes, y con su presencia tumbaron el mito de que "en Chile no hay negros» (Huenchumil, 2020). Levantaron una voz que se ratificó el 17 de abril de 2001 con la fundación de la ONG Oro Negro.

Desde ese momento y hasta el día de hoy se han creado numerosas organizaciones de reivindicación política y sociocultural en las provincias de Arica y Parinacota. Se debe reconocer, como lo hicieron Duconge y Lube (2014), que estas han realizado un sostenido esfuerzo de enunciación política y cultural, construido de manera transversal, que abarca redes nacionales e internacionales.

No obstante, asumiendo que el movimiento está inscrito en un proceso más amplio, para los objetivos de este trabajo abordamos la relevancia que ha teni- 
do la resignificación del tumbe carnaval para la consolidación de estos grupos como sujetos de interlocución ante el Estado. Y entendemos, además, que su performance habilita un espacio en el que se encarnan y proyectan memorias y prácticas culturales propias de este pueblo. Todo ello ha generado procesos de autorreconocimiento y ha ampliado su cuerpo social.

\subsection{Encarnar el pasado-presente. El rescate del tumbe carnaval}

Tal como ha sido mencionado por diversos investigadores, es en este contexto de reivindicación política cuando diversas personas adscritas a la ONG Oro Negro deciden desarrollar un proyecto FONDART ${ }^{11}$ en el año 2002 para «la creación de un grupo de danzas y música negra», lo cual permitió el rescate del tumbe carnaval. Si bien este impulso fue encabezado por integrantes de la familia Salgado, pronto se convirtió en un trabajo colectivo, pues se realizó un llamado a la participación entre las familias afrodescendientes locales, y algunas de ellas se interesaron y se incorporaron a la ONG (León, 2017; Carrasco, 2019).

Por ello, a partir de historias fragmentadas transmitidas por la memoria oral de los abuelos y abuelas afrodescendientes, tanto del valle como de la ciudad, se descubrió un elemento que se repetía en sus declaraciones; y es que, en el contexto del carnaval, las familias se reunían para festejar: en un momento dado formaban una ronda en la cual iban girando al son de guitarras y quijadas de burro; algunos recuerdan la presencia de bombos andinos y que se percutían todo tipo de utensilios que tuvieran a su disposición, como sillas, ollas o palmas, así como que cantaban coplas.

En medio de la ronda, una pareja formada por un hombre y una mujer comenzaba a bailar de forma improvisada, y, generalmente, el hombre le coqueteaba y molestaba. La mujer se desplazaba bailando, él la seguía hasta que «en ese momento alguien gritaba "tumbaaa" y la mujer comenzaba a darle caderazos al hombre para botarlo al suelo».12 Esta práctica, la ronda del denominado entonces tumba carnaval, no pudo ser mantenida debido al proceso de chilenización, y fue desapareciendo durante el transcurso del siglo xx.

Sobre la base de esta rememoración, el rescate de la performance del tumbe carnaval se produjo debido a un proceso de agencia reflexiva que surgió a partir de tradiciones construidas históricamente, pero también estuvo determinado por paradigmas ideológicos, políticos y estéticos marcados por el nuevo contexto.

Debemos considerar que muchas actividades desarrolladas por las familias afroariqueñas comparten elementos culturales y relaciones sociales con poblaciones indígenas, como la aymara, debido a las relaciones interétnicas que se mantienen en el territorio (Báez, 2019). Del mismo modo, tradiciones que tienen

11. El Fondo Nacional de Desarrollo Cultural y las Artes (FONDART) es un fondo concursable administrado por la Subsecretaría de las Culturas y las Artes del Gobierno de Chile.

12. Entrevista realizada por el autor a Carolina Letelier Salgado el 1 de marzo de 2019. 
un origen castellano o criollo han sido incorporadas a su bagaje cultural, sumadas y sincretizadas con prácticas culturales que provienen del continente africano. Asimismo, las identidades ya no son analizadas como unitarias, pues existen significantes de clase, género y sexualidad, entre otros, que ocasionan un «campo de posicionalidades», donde pueden producirse múltiples identificaciones (Hall, 2019: 143-144).

No obstante, debido a la politización identitaria afrodescendiente, debía incidir una manifestación que enfatizara la diferencia y que hiciera referencia directa a la «cultura negra» (Frigerio y Lamborghini, 2011). Con ello, y volviendo a la tesis de Jelin (2012: 42), observamos que el pasado activado en el presente fue objeto de una relectura en función de un futuro deseado. Este hecho posibilitó que experiencias y sentidos rememorados fueran moldeados según el «horizonte de expectativas».

De alguna forma tratamos, y me sumo ahí, de no afroindigenizar el tema [...] los tambores del carnaval eran andinos, tenía una relación indígena, con lo aymara. Y allí decidimos, con Gustavo del Canto y Yoni Olis, que fueron los impulsores de la rítmica, africanizar este movimiento a través de instrumentos y ritmos. ${ }^{13}$

Es así como, a través de un proceso de tradicionalización, surgió una performance cultural que logró articular la memoria colectiva local, pues a través de cánticos, coreografías y pasos encarnaron las labores agrícolas que eran desarrolladas en el valle de Azapa, sustento por siglos de muchas familias afroariqueñas de ascendencia colonial (León, 2017; Carrasco, 2019). Sin embargo, a su vez, se generó una producción de sentidos que les conectó dentro de un movimiento reafricanizador (Daponte, 2019). Esto último se debió a que adoptaron préstamos culturales, ritmos, instrumentos, movimientos corporales y vestimentas que aluden a diversas manifestaciones de la diáspora africana (Wolf, 2019).

Respecto a su instrumentación, en las dinámicas de comparsas actuales, generalmente la estructura que se establece es que por cada repique se conforman dos o tres bombos, un shekere/güiro y una campana. ${ }^{14}$ Esta conjunción genera una polirritmia muy rica en la que se producen ciclos en que predominan la alta sonoridad y la velocidad en la ejecución instrumental, en combinación con cortes y quiebres que dan paso a secciones donde se disminuye notablemente la intensidad sonora, y se abre el espacio para entonar canciones largas o ritmos y bailes más cadenciosos y «de tierra». Ello genera cambios en la energía del ambiente. ${ }^{15}$

13. Entrevista realizada por el autor a Cristian Báez el 5 de marzo de 2019.

14. Inicialmente fue constituida por el bombo y tambora a cordeles, la quijada de burro y la campana. No obstante, adaptar una instrumentación que permitiera su desplazamiento con buena sonoridad fue definitorio a la hora de sustituirlos por nuevos instrumentos. Por ello, tal como sucedió con la morfología de la danza, los instrumentos se definirán según cuestiones de movilidad, practicidad, estética y sonoridad. Para una mayor comprensión de su evolución, véanse: Carrasco (2019) y Domingo (2021a). 2021).

15. Al respecto, véase el registro: https://youtu.be/IUd8wpe8AIA (consulta: 26 de febrero de 
Actualmente, existen seis comparsas afroariqueñas que practican y difunden el tumbe: Oro Negro, Lumbanga, Tumba Carnaval, Arica Negro, Renacer Afro y Palenque Costero. ${ }^{16}$ Asimismo, integrantes de diversas comparsas han creado y se han insertado en grupos de música y centros de proyección folclórica que difunden la danza, ejecución musical y canto del pueblo afroariqueño, junto con otros géneros afrolatinoamericanos, en eventos públicos y privados sobre un escenario. Estos grupos son: Sabor Moreno, Alza Raza, Aluna Tambó, Mixtura Negra de Arica, los Barrileros de Arica o Carlos Aníbal y los Morocos.

\section{2. ¡Se presentan los afroariqueños!}

El 5 de enero del 2003, en el marco de la historia aquí narrada, un grupo pequeño de Oro Negro salió a celebrar un evento denominado la Pascua de Negros, hecho que los situó, por primera vez, en la portada de La Estrella de Arica, un diario regional (Daponte, 2019: 11; León, 2017: 98; Wolf, 2019: 57). Esto ha sido referido por investigadores y por los propios integrantes de las comparsas como un «antes y un después» dentro del proceso de rescate y, particularmente para el caso del tumbe carnaval en comparsa, es destacado como su fecha fundacional.

Fue ese día cuando nosotros salimos por las calles de Arica a partir de la reivindicación y después de mucho de que no se bailaba o no se tocaba tumbe. Entonces eso fue un hito muy importante que marcó un antes y un después dentro de la ciudad. La gente nos miraba, y ¿ustedes de qué país son? ${ }^{17}$

En esta línea, el primer acto público en la capital fue realizado un año después, en enero de 2004, cuando más de 80 integrantes de Lumbanga, organización fuertemente enraizada con Azapa, viajaron a Santiago gracias a un fondo que obtuvieron para la promoción de la cultura afrodescendiente. Tal como nos comentó Cristian Báez, la gente se extrañaba cuando descubrían que eran chilenos, pues su imaginario llevaba a situarlos en Brasil.

Nuestro interés en destacar estos acontecimientos radica en su dimensión política: a partir de ellos emergió un nuevo mundo de posibilidades, ya que, pese a las secuelas perpetradas por la chilenización, una serie de personas se apropiaron de sus corporalidades con autoafirmación positiva y ocuparon el espacio público. Así se comenzó a subvertir la representación negativa que les invisibilizaba

16. En este trabajo se hace alusión a las comparsas afroariqueñas. Existen comparsas en Iquique, La Serena, Tocopilla, Copiapó, Antofagasta, Santiago, Valparaíso y Concepción, entre otros lugares, sin embargo, sus participantes toman Arica como punto referencial, respetando la cultura afroariqueña. Por ello, en su mayoría han viajado a Arica y también han invitado a sus ciudades a los principales exponentes del movimiento afroariqueño para instruirse en talleres de danza y percusión, en los cuales, además, se trabaja la parte histórica y sociocultural (Allende, Amigo y Rojas, 2019).

17. Entrevista realizada por el autor a Carolina Letelier Salgado el 1 de marzo de 2019. 
o discriminaba desde la sociedad dominante. Este fue un paso político imprescindible constituido a través del diálogo «entre cuerpos», por su hacer y sentir, y que produce experiencias relacionales y físico-afectivas que fueron clave por articular la comunidad afroariqueña (Bulo, 2019).

Esta vinculación de cuerpos posee un significante sociopolítico intrínseco que ayuda a recomponer el tejido social. Como expresa Butler (2017: 154), estas reclamaciones corporeizadas públicas son indispensables para la comprensión y constitución de todo pueblo, para «lograr imponer una acción y un discurso que sean reconocidos por la sociedad».

[...] están ejercitando un derecho plural y performativo a la aparición, un derecho que afirma e instala el cuerpo en medio del campo político, y que, amparándose en su función expresiva y significante, reclaman para el cuerpo condiciones económicas, sociales y políticas que hagan la vida más digna (Ibídem: 18).

Asimismo, a través de estos actos y a partir de la noción de estética abordada por Ranciére (2009), sostenemos que la práctica del tumbe carnaval generó una nueva distribución de lo sensible, esto es, articuló nuevos modos de sentir, de ver, de escuchar y de hacer, que conllevan un nuevo ordenamiento de cuerpos y una nueva asignación de sus lugares y funciones con relación a un orden social.

De este modo, el 5 de enero de 2003 se produjo la primera «escena de disenso» que cuestionó la distribución de poder y que interrumpió el orden establecido y su dominación. Esta «introducción de lo heterogéneo» alteró el reparto de lo sensible, en la medida en que intervino sobre aquello que podía ser manifestado en la esfera pública. Y esta nueva experiencia político-sensorial, además, se configuró a partir de lo común, de la acción colectiva.

Eso fue lo que les permitió acceder a una «zona visible» para su cobertura mediática. La Estrella de Arica, en sus páginas centrales, informó a la población local acerca de esta manifestación cultural, pues Omar Letelier, quien por aquel entonces ejercía de secretario ejecutivo de Oro Negro, declaró:

En el tiempo de la colonia, cuando los negros llegaron a la zona trajeron estos bailes de África y con el tiempo esta danza se fue perdiendo entre los afrodescendientes, pero a través de este carnaval y el proyecto que nos adjudicamos -FONDART - queremos recrear estas tradiciones. ${ }^{18}$

A su vez, el diario presentó el tumbe carnaval como «el puente místico y musical» que permitía que «la danza cultivada en el valle de Azapa» se ejecutara "Con alegría y cadencia» en las principales calles del casco antiguo de la ciudad. También, a través de las imágenes y de lo escrito en el diario, se mostraron tanto las vestimentas de las bailarinas, «ataviadas a la usanza de la mujer afrodescendiente», como los instrumentos: «Los músicos, golpeando grácilmente los

18. "Carnaval de color en "Pascua de Los Negros"». La Estrella de Arica, 6 de enero de 2003, A-5 [pág. 5]. 
"bombos" y las "tamboras", junto al cascabeleo de las quijadas de burro - esqueleto utilizado como instrumento musical $\longrightarrow »{ }^{19}$

Se puede afirmar que, desde el momento en que se presentó la primera comparsa gracias a la ONG Oro Negro, la prensa local cumplió con un rol importante en la difusión medial de las actividades desarrolladas por este pueblo. Además, conforme el movimiento fue adquiriendo renombre, medios nacionales e internacionales fueron haciéndose eco de sus actuaciones.

\subsection{Resignificar el pasado silenciado, la memoria emblemática del tumbe carnaval}

Anteriormente, hemos defendido que el traumático período de la chilenización provocó la cancelación de las memorias no permitidas por la nueva soberanía impuesta, hecho que generó un olvido social de tradiciones y costumbres del pueblo afroariqueño. No obstante, la producción de memoria puede ser constitutiva de las luchas sociales y políticas, ya que el recuerdo es vital para los movimientos sociales que demandan reconocimiento (Jelin, 2012).

En este sentido, ante una narrativa y un modelo educacional que negaba su presencia, el pueblo afroariqueño articuló, a través del tumbe carnaval, su propia representación del pasado-presente, con miras también a un proyecto futuro. Ese fue un paso esencial que tensionó la amnesia institucional, pues provocó interferencias interpretativas del sujeto, que, ajeno a esta realidad, comenzó a escuchar/observar esta performance, lo cual determinó sus modos de comprensión.

De acuerdo con Steve Stern, todos poseemos memorias sueltas que no tienen mayor importancia fuera de la experiencia individual. Sin embargo, el pasado puede articular un sentido social y colectivo, y por ello este autor defiende la existencia de una memoria emblemática, «un marco o contexto que organiza el significado, la selectividad y la contramemoria» (Stern, 2009: 146). Esta está construida socialmente, pero eso no significa que sea una invención arbitraria, pues pretende captar «la verdad esencial sobre la experiencia colectiva de la sociedad» (Ibídem: 115).

Para que esta tenga éxito, debe circular en esferas públicas, y por eso el tumbe carnaval tiene un rol imprescindible, pues su narrativa sirve como ancla que otorga significado colectivo. Con esta idea presente, consideramos que estos «portavoces», gracias a su capacidad de agencia, negociaron con sus emblemas y elementos culturales, para resignificarlos en esta performance mediante una memoria emblemática que afirma su presencia.

Lo que hicimos fue tomar algunos aspectos y recrearlos en pasos que estuvieran asociados inicialmente a lo que eran las actividades en los valles, en la parte agrícola. Es así que algunos de los pasos base tienen que ver con la raima de la aceituna y hacerla calzar al tiempo con la cadera, ese fue como un trabajo de recreación. También está el paso del corte de la caña con el

19. Ídem. 
machete, ¿cierto?, o la recogida del algodón, y de ahí de ese mismo trabajo, nace también los pasos de avance [para desplazarse] o el mismo tiempo fuerte que es el de darse de caderazos. ${ }^{20}$

En esta misma línea, como indica Pamela Báez, fueron los recuerdos almacenados desde la niñez los que generaron la inspiración necesaria para incorporar estas historias del día a día en el baile.

Crecimos viendo a los abuelitos. Esos pasos los ligamos con nuestra abuelita Rosa y demás familias afro de acá, por las tradiciones y las labores de Azapa. Pensamos en cómo sacaban las aceitunas y las dejaban. Y la música, con la percusión, iban sacándola conforme iban saliendo los pasos. Sacábamos la aceituna y el ritmo se ajustaba al movimiento corporal. Cuando caía la aceituna a la comba sonaba el tambor. ${ }^{21}$

Vemos que uno de estos nudos de la memoria descansa en el valle de Azapa, lugar que se torna fundamental, pues es aquí donde la narrativa y el simbolismo afroariqueños se ligan con un territorio con alto valor patrimonial, material e inmaterial. Es por ello por lo que, si bien los membranófonos y su ejecución se conectan con el movimiento de la diáspora, la memoria emblemática, en cambio, se sostiene debido a que los primeros bombos y repiques fueron construidos a través de barriles de aceituna. Yoni Olis, lutier afrouruguayo radicado en el valle, y quien fue una de las personas clave por dar forma a estos instrumentos, remarca:

Es muy fácil caer en que eso es por el candombe y en mi opinión es un error. El barril estaba acá, ¿te das cuenta? Estábamos buscando elementos que estrecharan a la historia del afro de acá. ¿Cómo íbamos a dejar el barril de lado? Si en esa época era lo cotidiano en la vida del afro, por eso pasó a convertirse en el instrumento, en la caja musical. ${ }^{22}$

Como señala Taylor (2017), la performance transmite conocimiento, historia y memoria, así como identidad y emoción. Esto se produce gracias a actos de transferencia generados por las acciones encarnadas, que son reiteradas cada vez que se realiza la performance. Desde esta perspectiva, el tumbe carnaval encarna un repertorio donde se producen múltiples interacciones semióticas con este territorio, a través de pasos y movimientos coreográficos, instrumentos, las letras de lo que se canta o el vestuario, entre otros recursos simbólicos (figura 2). Y a la vez activa materiales de archivo, como en las ocasiones en que portan cuadros de sus ancestros. Con este acto de transferencia, se les rinde homenaje y recuerdo de manera pública, al insertar estas imágenes en el cuerpo social (Lamborghini, 2019).

Todo ello es generador de sentido e interviene en las subjetividades y en las posiciones identitarias de los performers. Por esta razón, defendemos que la

20. Entrevista realizada por el autor a Carolina Letelier Salgado el 1 de marzo de 2019.

21. Entrevista realizada por el autor a Pamela Báez el 27 de febrero de 2020.

22. Entrevista realizada por el autor a Yoni Olis el 26 de febrero de 2020. 
música-danza posee cualidades gestuales que se encuentran tanto en los gestos sonoros, como en los visuales, y que se desprenden de la ejecución musical y dancística, que nos arrastran a sentir y pensar en aspectos extramusicales (DeNora, 2004).

Figura 2. Agricultor de Azapa. Detrás, bloque de bailarines y bailarinas con caña. Carnaval Andino, 2019.

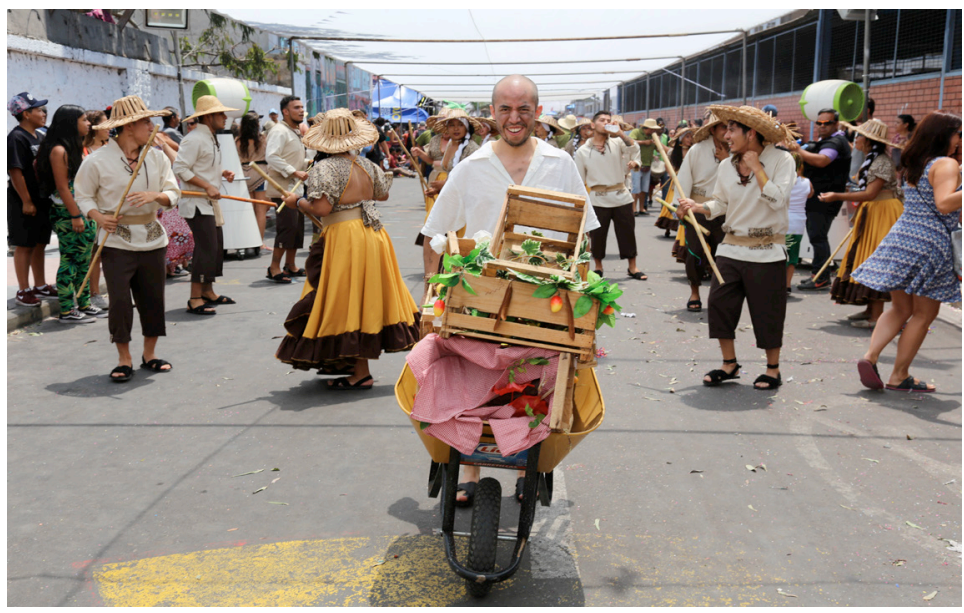

Fuente: Imagen del archivo personal del autor.

A su vez, la memoria emblemática debe ser capaz de generar un marco amplio y flexible de significación. Por ello, y en la medida en que el tumbe carnaval comenzó a establecerse como referente social, nuevos portavoces y memorias comenzaron a definir sus elementos identificatorios. Es así como la Comparsa Arica Negro, formada por las hermanas María, Aurora y Alba Lara en 2005, comenzó un trabajo de sensibilización de una zona costera de Arica conocida como La Chimba. Ello fue posible por la transmisión oral legada por su abuelo Manuel el Negro Lara.

Este sector, cercano al actual Campus Velásquez y al Casino de Arica, era una zona rica en recursos hídricos subterráneos, donde familias afroariqueñas disponían de huertos, con pequeños ranchos o estancias para su venta en la ciudad, y donde también se practicaba la pesca. Igualmente, las mujeres realizaban actividades de lavandería para familias adineradas (Báez, 2012: 32-33; Díaz, Muñoz et al., 2019). «En la chimba corría agüita todo el día, había huertos, se vivía del mar y del pescado, de la cocinería y la lavandería».23

Esta identificación con la costa derivó en un proceso de tradicionalización que contiene diferencias en su performance; por eso, abundan referencias semióticas que remiten al mar y a las labores que allí se practicaban. De esta ma-

23. Entrevista realizada por el autor a Aurora Lara el 26 de febrero de 2020. 
nera, aunque portan los mismos instrumentos y base rítmica, hay pasos diferentes (como el de la malla, que recrea la actividad pesquera, o como el de lavar) y que son reforzados por contenidos textuales y cantos propios. "Simulamos lo que se hacía en la chimba, pero lo amoldamos al ritmo, tiramos la red, el pescar, lavar, colgar y sacudir la ropa. Por eso no hacemos el paso del algodón».24 Esta memoria emblemática también se encarna en el vestuario, por ello, vemos que portan mallas o conchas: «nuestros chicos y chicas que tocan tambores suelen llevar su red para pescar, con su gorrito, en las faldas también llevamos muchas veces partes de redes». ${ }^{25}$

\section{El tumbe carnaval como práctica emancipatoria}

Este proceso de tradicionalización convirtió al tumbe carnaval en un potente instrumento político, puesto que, además de servir para denunciar el racismo estatal, que ponía trabas a la propuesta de activar medidas con el objetivo de que la población afrochilena fuera legalmente reconocida, sirvió también para interpelar al conjunto de la sociedad que, por tanto tiempo, había desconocido a esta población y la había relegado a una zona de invisibilidad.

Por ello, más que analizarla como acompañante del proceso etnopolítico, conviene recordar que esta práctica cultural se constituyó en un repertorio para la acción del movimiento social afroariqueño. Hoy en día sigue incidiendo en diversas reivindicaciones para que se garanticen los derechos de esta población en materia de educación, salud, territorio, vivienda y promoción de su identidad cultural, así como para que sus miembros sean incluidos en los censos y en la toma de decisiones políticas.

Por tanto, es posible entenderla como una práctica emancipatoria, lo cual significa reconocer la potencialidad que tiene el sonido al «desarrollar argumentos sobre la lucha social y la política» (LaBelle, 2018: 2). El sonido puede transmitir mensajes a través de las vibraciones y los ecos que rebotan sobre las estructuras de dominación, «consiguiendo un impulso y una dirección al escuchar y ser escuchados, al hacer sonar o no acústicas particulares de reunión y resistencia» (Ibídem: 4). Para el caso afroariqueño en concreto, su resonancia ayudó a cohesionar a un pueblo que habitaba la no-existencia, desde el punto de vista de la narrativa hegemónica estatal, y consiguió en menos de dos décadas su reconocimiento legal por parte del Estado.

En este sentido, el tumbe carnaval ha logrado cambiar el paisaje sonoro local. Hoy en día, caminar por las calles de Arica significa exponerse a una experiencia pluriétnica y pluricultural. Se pueden encontrar diferentes músicas y bailes asociados con el mundo andino, como tarqueadas, morenadas, tinkus y tobas, entre otros. No obstante, hoy en día se evidencia firmemente la idea afro asociada al imaginario que proviene del proceso de globalización de la diáspo-

24. Entrevista realizada por el autor a María Lara el 26 de febrero de 2020.

25. Entrevista realizada por el autor a Alba Lara el 26 de febrero de 2020. 
ra africana (Daponte, 2019; Wolf, 2019). En este sentido, el lutier afroariqueño Francisco Pancho Piñones relata:

Lo que pasa acá en Arica no ocurre en otros lados. Tú estás así tranquilo y de repente escuchas tambores, «ahh, están tocando tumbe carnaval», o, si no, escuchas varios tipos de música de varias culturas porque ensayan, no sé, caporal, por ejemplo. Después escuchas bailes religiosos por otra parte. En otra ciudad los autos nada más, cualquier cosa menos música o los sonidos que son de la cultura. Llegamos a conquistar este espacio público y del inconsciente. ${ }^{26}$

Por eso, consideramos el sonido y la danza como elementos que conquistan espacios, a la vez que articulan procesos de identificación. Pero ¿en qué medida el sonido, al igual que la performance pública, puede legitimar la aparición y el reconocimiento de grupos étnico-raciales? Las primeras veces que las personas salieron interpretando y danzando tumbe carnaval por las calles ariqueñas, los propios vecinos desconocían su procedencia y asociaban estos eventos con una manifestación exótica o extranjera. Hoy en día, sin embargo, se ha legitimado socialmente como una música-danza local, originaria del pueblo afrodescendiente, que se ha insertado en espacios escolares formales a través de clases o talleres extracurriculares o en presentaciones y galas folclóricas $(\mathrm{He}-$ redia, 2018).

Evidentemente, el sonido y la performance del tumbe carnaval establecen un perímetro acústico que es capaz de delimitar una frontera simbólica ${ }^{27} \mathrm{y}$, como afirman sus cultores, «es una forma de avisar a la población, este territorio también es nuestro, aquí estamos. Hace que la gente nos identifique y diga: "Ahí vienen los afros bajando"».28

Y es que, una vez se está en Arica, se asocia rápidamente el sonido producido por la instrumentación utilizada por las comparsas del tumbe carnaval, así como sus patrones coreográficos, gestualidades y vestimenta. En suma, es el sonido el que provoca que se puedan reconocer las comparsas aun cuando no sean visibles pues la escucha de su plano sonoro permite construir una imagen mental de su ubicación y de su identidad cultural encarnada en su performance.

Como advierte Daponte (2019), resulta pertinente resaltar que el gobierno de la ciudad de Arica fomenta una actividad cultural de ámbito carnavalero que se moviliza durante todo el año. Su expresión más celebrada es el Carnaval Andino con la Fuerza del Sol, en el cual un total de 64 comparsas de distintas danzas desfilan durante tres días ante miles de personas, y en este evento el pueblo afroariqueño escenifica la diferencia con tres agrupaciones. Asimismo, por iniciativa de Lumbanga, en febrero de cada año se produce la bajada del Car-

26. Entrevista realizada por el autor a Francisco Piñones el 24 de febrero de 2020.

27. Tomando a Rivas (2015: 89), «[el sonido] es susceptible de vehicular sentido, la aparición o presencia de un sonido puede detonar conflictos simbólicos, lucha de signos, conflictos entre polos de significado. La condición política del sonido asume [...] que se establece y opera en los juegos de poder simbólico".

28. Entrevista realizada por el autor a Carolina Castillo el 25 de febrero de 2020. 
naval Afrodescendiente. Y también se realizan carnavales de carácter barrial en los valles y pueblos del interior. En este sentido, como afirma Ardito (2014), el carnaval es uno de los espacios de aparición privilegiados para escenificar tensiones y reivindicaciones político-culturales e identitarias.

Sin embargo, esta reapropiación del espacio público y sonoro ariqueño no se produce únicamente durante estas festividades, ya que las agrupaciones afroariqueñas realizan sus ensayos al aire libre. Este hecho hace que sean públicos y que constituyan parte del paisaje cotidiano de la ciudad. Aquí debemos considerar la materialidad intrusiva que posee el sonido, y cuya presencia transgrede fronteras entre lo público y lo privado al traspasar muros y ventanas, por lo que penetra en nuestra esfera privada, en nuestra intimidad (Domínguez, 2015).

Una vez logrado este espacio de aparición, es decir, cuando el tumbe carnaval es reconocido como parte del repertorio del pueblo afroariqueño, es cuando puede incidir en la consecución de reivindicaciones político-sociales. En un principio, el principal objetivo planteado por los activistas, aparte de nuclear a la población afrodescendiente local, fue el de lograr ser censados y reconocidos políticamente por el Estado chileno.

Por ello, en 2004 comenzaron a pedir formalmente que se incluyera en los censos a las personas afrodescendientes, sobre todo con vistas a que fueran incorporadas en el que estaba programado para 2012 dentro de la agenda nacional. Durante estos primeros pasos, se buscó el apoyo de senadores y diputados regionales; no obstante, en esta primera etapa no encontraron ningún respaldo político.

Ya en el 2009, con la ayuda de fondos otorgados por el gobierno regional y contando con el apoyo mostrado por el intendente Luis Rocafull, diversos activistas iniciaron algunas acciones en la ciudad de Arica y en Azapa, como llevar encuestas para contabilizar el autorreconocimiento de la población afro. Ello, además, fue reforzado por la presencia de personeros nacionales y por agencias internacionales, como el PNUD (Soto, 2019).

No obstante, a pesar de este esfuerzo político y organizativo, los afrochilenos fueron excluidos del censo de 2012. En 2011, conscientes de que esta lucha legislativa no iba a culminar con éxito, el pueblo afroariqueño inició diversas protestas tanto en la Intendencia como en el centro de la ciudad (figura 3). Esta movilización social fue articulada mediante el tumbe carnaval.

Tal como nos relató Marta Salgado, esta presión ejercida, que incluso tuvo la cobertura de medios de televisión, provocó la firma de un convenio con el gobierno regional en octubre del 2011 para realizar una encuesta de caracterización de la población afrodescendiente en la región de Arica y Parinacota. Este fue uno de los primeros logros políticos, necesario para «definir políticas públicas y focalizar recursos con pertinencia cultural y enfoque de derechos» (Guerra y Büchner, 2019: 72). ${ }^{29}$

29. Para el 2014 los resultados fueron que, de un total de población encuestada de 179.172 habitantes, el $4,7 \%$, correspondiente a 8.415 personas, se reconocieron como afrodescendientes. Es 
Figura 3. Movilización por la inclusión en el censo de 2012.

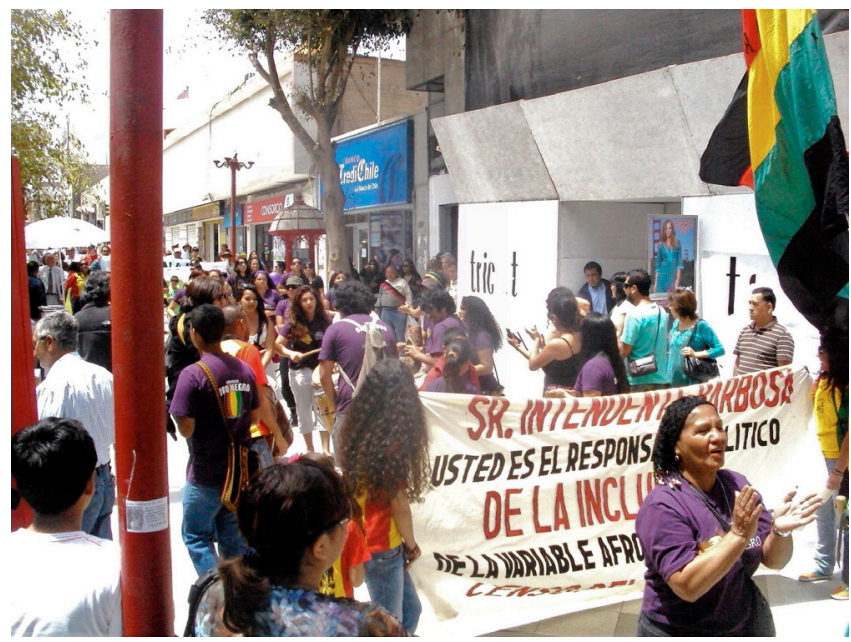

Fuente: Imagen en Archivo de la ONG Oro Negro.

Evidentemente, este uso político también ha estado presente en las demandas de reconocimiento estatal. En nuestro análisis, defendemos que esta expresión cultural se convierte en un exitoso imán para un extraño que se encuentra de paso y que se siente llamado a acercarse por el sonido de las campanas, de las voces y cantos, de bombos, shekeres o repiques. Puede señalarse como ejemplo el 14 de abril de 2016, cuando diversas organizaciones afroariqueñas llegaron hasta el Congreso para acompañar al ya diputado Luis Rocafull que iba a entregar el proyecto de ley de reconocimiento del pueblo afrochileno y, posteriormente, realizaron un pasacalle por las principales vías peatonales del centro de la capital (figura 4).

Ese oído al paso, es decir, aparecer de improvisto en el escenario público, proyecta un sonido que irrumpe en la cotidianidad de las personas que se encuentran en ese lugar. El tumbe carnaval produce una «escucha dentro de la oscuridad» y emite un sonido que siempre se mueve y traslada hacia otro lugar. «Lo itinerante permite modalidades y formaciones de acción que desestabilizan explícitamente las fronteras; esto transgrede y entrega conocimientos particulares, así como fantasías e imaginarios» (LaBelle, 2018: 19).

Además, mediante esta performance conforman un archivo y repertorio político a través de pancartas y carteles que portan en la cabecera de la comparsa, y en ocasiones también llevan adheridas imágenes o textos que facilitan la transmisión de un mensaje que ellos mismos han predeterminado. A través de estos actos de transferencia trascurren memorias, sonoridades, acciones y manifiestos (Taylor, 2017). 
Figura 4. Pasacalles por el paseo Ahumadas de Santiago de Chile, 14 de abril de 2016.

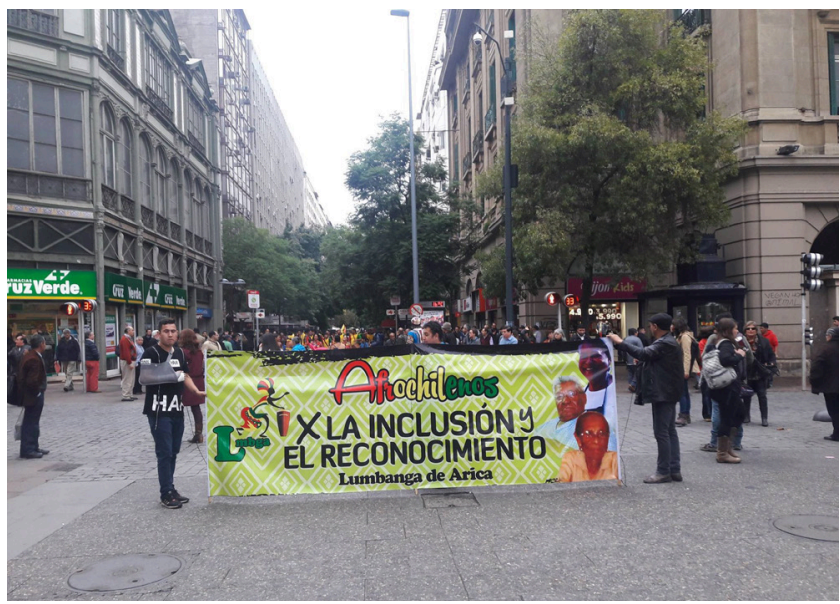

Fuente: Imagen en Archivo de la Organización Lumbanga.

Por otra parte, la necesidad de mantenerse juntos en el tiempo, mediante un movimiento rítmico coordinado constante, genera una serie de sentimientos compartidos que, como afirmaron sus participantes, provocan estados de euforia. Esta vinculación muscular es clave, pues origina relaciones de interconexión y crea un proceso experiencial que permite percibir el yo como un nosotros (Allende et al., 2019).

Estas sensaciones han sido transmitidas durante el carnaval afroariqueño por medio de aseveraciones como «los tambores nos hablan», o cuando los músicos comentan que «el bombo se conecta con la cadera». Dichas conexiones también son transmitidas hacia el público gracias a la percepción simultáneamente visual y auditiva, debido a los diferentes cortes que la percusión realiza durante el acto performativo, y cuya señal acústica indica cambios en la dinámica coreográfica que son visibles para el público presente.

Por ejemplo, uno de los momentos en que se produce un corte dentro de la ejecución sonora es el instante en que se señala el golpe de caderas que se produce en el bloque de danza, con el paso tumbe. De este modo, la sonoridad, el baile y la escucha interactúan mediante un conocimiento activo que facilita la interacción del grupo. Por tanto, puede decirse que la performance del tumbe carnaval articula un modelo de comunidad y una forma de sociabilidad que se encuentra atravesada por lo sonoro y lo corporal.

Al danzar una está relatando una historia, entonces al transmitir esa historia también sientes el sonido, el repique o el bombo [que] en este caso va apoyando. Por ejemplo, el machete [paso de corte de caña] lo marca, le da más intensidad a ese movimiento, a ese paso. Justo cuando el brazo baja sientes el «pa», lo marca e intensifica. Lo gritamos. ${ }^{30}$

30. Entrevista realizada por el autor a Carolina Castillo el 25 de febrero de 2020. 
Esta performance cultural, además, viene reforzándose debido a la continuidad intergeneracional que se produce dentro de ella, donde al menos tres generaciones la cultivan actualmente: abuelas con sus hijos y nietas. Así se garantiza la sostenibilidad del movimiento social y cultural, gracias a los compromisos afectivos y emocionales que se originan entre sus participantes.

\begin{abstract}
Las chicas embarazadas salen al lado de los tambores, con la guatita ahí, el niño ya va recibiendo eso. $Y$ esos chicos luego tocan espectacularmente bien, ¿te das cuenta? Cuando esos niños crezcan van a ser el futuro de la agrupación. Eso se está dando ya, la transmisión generacional. Eso es importante, quiere decir que, si mañana no vas o moriste, la cosa va a funcionar igual. ${ }^{31}$
\end{abstract}

Por tanto, las organizaciones y comparsas han sabido utilizar, mediante la agencia y un proceso de tradicionalización, esta «nueva estructura de oportunidades» que otorga el multiculturalismo (Frigerio y Lamborghini, 2011). De esta manera han logrado posicionarse dentro del circuito de la cultura, pero también de la política pública regional y nacional. ${ }^{32}$ Así, el goce y la emotividad de danzar-tocar juntos se vincula con los objetivos de una lucha compartida en escenarios de negociación y disputa, que son mediados gracias a la articulación de un tumbe carnaval resignificado políticamente (Lamborghini, 2019).

\title{
5. Consideraciones finales
}

Como ha sido constatado, y aun defendiendo las posiciones que sitúan la performance del tumbe carnaval en un movimiento de rescate cultural, en estas páginas hemos reivindicado su dimensión política.

Por una parte, sostenemos que retumbó en la política local y nacional, al ser vehiculizado como un medio denunciante que delimitó una marca sonora y visual que visibilizó/sonorizó la distinción social. Esta presencia de la diferencia, como vimos, se sustentó en una práctica cultural que evoca imaginarios y movimientos afrodiaspóricos, junto con su propia memoria y pertenencia cultural local. A ello le debemos sumar, además, el hecho de que se produjo una reapropiación de sus memorias y del espacio público y sonoro ariqueño, lo que posibilitó romper con el proyecto negacionista nacional.

Además, su práctica le permitió al pueblo afroariqueño combatir un universo simbólico y político-social lleno de asimetrías, subvirtiendo prejuicios y discriminaciones a través del goce del movimiento corporal. Esto fue posible gra-

31. Entrevista realizada por el autor a Yoni Olis el 26 de febrero de 2020.

32. Algunas voces críticas han denunciado su inserción en ambientes institucionalizados, que fomentan dinámicas de mercado cultural y que lo objetivan como producto de consumo y disfrute. Esto se debe a que generó una objetivación de su práctica y una imposición de modificaciones que iban más allá de su propia dinámica de cambio. No obstante, este análisis se escapa de los objetivos planteados en este trabajo. Véanse: Wolf (2019) y Domingo (2021a). 
cias a la capacidad que tiene el sonido de producir emociones, reconocer al otro como un nosotros y crear vínculos afectivos que articulan comunidad.

Por último, debemos destacar que su performance ha generado procesos de identificación y adhesión en personas que antes no se reconocían como afrodescendientes. Es un artefacto cultural que provoca enganches (así los denominan en las comparsas), por lo que favorece la producción de subjetividades que intervienen en las posiciones identitarias de sus performers.

Aun así, no todos los integrantes de las comparsas se autorreconocen como afrodescendientes, pues estas se han establecido como un gran referente social que ha generado toda una cultura juvenil urbana no necesariamente vinculada a esa autoidentificación. Sin embargo, aquellos que se comprometen con los valores y tradiciones de este pueblo comparten un compromiso colectivo con el movimiento político-social, que además viene potenciado por las relaciones de vecindad, amistad y coexistencia en el mismo territorio.

Para finalizar, queremos exponer una breve consideración a raíz de la promulgación de la Ley núm. 21151, y es que su aprobación todavía no ha supuesto ningún cambio efectivo. Por ejemplo, a pesar de que en su artículo 5 se establece que el pueblo afroariqueño debe ser sujeto de consulta cada vez que se produzcan medidas legislativas o administrativas que puedan afectarles, esto no se ha cumplido. Y el caso más llamativo es que, en el marco del nuevo proceso constituyente que se ha abierto en Chile a raíz de la revuelta popular iniciada en octubre de 2019, el pueblo afrodescendiente ha sido excluido de la asignación de escaños reservados, algo que sí han obtenido los pueblos indígenas. Esto es muestra de políticas multiculturalistas vacías y simbólicas que inciden en reconocimientos y beneficios para proyectos culturales, pero no conceden espacios de poder, derechos políticos o territoriales (Duconge y Lube, 2014).

Ante ello, el 11 de diciembre de 2020, tanto dirigentes sociales como activistas volvieron a la Intendencia de Arica para intentar dialogar con los funcionarios allí presentes. Una vez más, y se seguirá haciendo cada vez que no se alcance una justicia social real, los cuerpos, los tambores y los cánticos proyectaron un sonido político y de resistencia: «Eeeeh, jtumbeee!».

\section{Bibliografía}

Ahumada, Margarita (2015). Afrodescendientes en Arica: «Renacer danzando». Tesis de grado. Universidad de Tarapacá.

ALARCÓN, Javiera; ARAYA, Isabel y CHÁVEZ, Nicole (eds.) (2017). Identidad negra en tiempos de chilenización: memorias de abuelos y abuelas afrodescendientes de Arica y el vaIle de Azapa. Santiago de Chile: Consejo Nacional de la Cultura y las Artes.

Allende, Ana; Amigo, Ricardo y RoJAs, José (2019). Danza afro en Chile: abriendo caminos. Santiago de Chile: Fondo Nacional de Desarrollo Cultural y las Artes.

Álvez, Amaya e IRARRÁZAVAL, Andrés (2000). «El plebiscito sobre el destino de Tacna y Arica como solución jurídica a un conflicto bélico. El aporte de Federico Puga Borne». Revista de Estudios Histórico-Jurídicos, Valparaíso, 22, págs. 193-212. 
ARDITO, Lorena (2014). "Cuando don Carnal se viste de negro: la negritud nuestroamericana entre "lo negro" y "lo afrodescendiente" ». Latinoamérica. Revista de Estudios Latinoamericanos, Ciudad de México, 59, págs. 223-249.

ARTAL, Natalie (2012). «A(f)rica: relatos y memorias afrodescendientes en Arica tras la chilenización y el conflicto entre Perú y Chile (1883-1929)». Aletheia. Revista de la Maestría en Historia y Memoria de la FaHCE, Ensenada, 4, págs. 1-16.

BÁEZ, Cristian (2012). Lumbanga: memorias orales de la cultura afrochilena. Coquimbo: Centro Mohamed VI para el Diálogo de Civilizaciones.

BÁEZ, Cristian (2019). Relaciones sociales y culturales afroindígenas en el norte de Chile, desde la negación al reconocimiento. Cambridge: The ALARI First Continental Conference on Afro-Latin American Studies.

BuLo, Valentina (2019). Sobre el placer. Madrid: Síntesis.

BuLO, Valentina у Ото, Alejandro de (2015). «Piel inmunda: la construcción racial de los cuerpos». Mutatis Mutandis: Revista Internacional de Filosofía, Santiago de Chile, 5 , págs. 7-20.

BUTLER, JUDITH (2017). Cuerpos aliados y lucha política. Hacia una teoría performativa de la asamblea. Barcelona: Paidós.

CARRASco, Ignacio (2019). «De Azapa vengo bajando». Una antropología musical del tumbe carnaval afroariqueño: conformación, desarrollo y prácticas de la colectividad tumbera. Memoria de título de Antropólogo Social. Universidad de Tarapacá.

DAPONTE, Jean Franco (2019). Aunque no suena tan negro, es música de negros. Presencia y aporte de los esclavos africanos a la música tradicional del Norte Grande de Chile. Tesis doctoral. Universidad de Valladolid.

DeNora, Tia (2004). Music in everyday life. Cambridge: Cambridge University Press.

DíAZ, Alberto; BRIONES, Valentina y SÁNCHEZ, Eugenio (2019). "Afrodescendientes en Arica. Registros coloniales para una historia regional». En: DíAZ, Alberto; GALDAMES, Luis y Ruz, Rodrigo (coords.). ... y llegaron con cadenas... Las poblaciones afrodescendientes en la historia de Arica y Tarapacá (siglos XVII-XIX). Arica: Ediciones Universidad de Tarapacá, págs. 29-65.

Díaz, Alberto; MuÑoz, Wilson y LANAS, Paulo (2019). «Censos y disensos en Arica, Azapa y Lluta. Apuntes sociodemográficos de los afrodescendientes durante el siglo XIX». En: Díaz, Alberto; GaldAMES, Luis y Ruz, Rodrigo (coords.). ... y llegaron con cadenas... Las poblaciones afrodescendientes en la historia de Arica y Tarapacá (siglos XVII-XIX). Arica: Ediciones Universidad de Tarapacá, págs. 227-407.

Domingo, Daniel (2021a). «El negro de Arica, el negro llegó». Narratividad musical y «performance» del tumbe carnaval en la articulación sociopolítica afrodescendiente del extremo norte de Chile. Tesis de magíster. Universidad Alberto Hurtado.

Domingo, Daniel (2021b). «Afrodescendencia negada. Ocultamiento del ser y apropiación del aporte negro en Chile. Una aproximación histórico-musical». A Contracorriente: una Revista de Estudios Latinoamericanos, Raleigh, 18, págs. 213-238.

Domínguez, Ana (2015). «Ruido: intrusión sonora e intimidad». Inmediaciones de la Comunicación, Montevideo, 10, págs. 118-130.

Duconge, Giselle y LUBE, Menara (2014). «Afroariqueños: configuraciones de un proceso histórico de presencia». Estudios Atacameños, San Pedro de Atacama, 49, págs. 129-151. 
ECheVERRI-PInedA, Cristina (2020). «Normas internacionales para afrodescendientes en América Latina: interacción entre movimientos sociales, Estados e instituciones internacionales». Colombia Internacional, Bogotá, 102, págs. 139-164.

ESPINOSA, María (2015). «Afrochilenos en Arica: identidad, organización y territorio». Antropologías del Sur, Santiago de Chile, 3, págs. 175-190.

FrIGERIO, Alejandro y LAMBORGHINI, Eva (2011). «(De)mostrando cultura: estrategias políticas y culturales de visibilización y reivindicación en el movimiento afroargentino". Boletín Americanista, Barcelona, 63, págs. 101-120.

GuERRA, Felipe y BÜCHNER, Catalina (2019). «La demanda del pueblo afrochileno por el reconocimiento: La construcción del derecho a la visibilidad estadística». Anuario de Derechos Humanos, Santiago de Chile, 15, págs. 65-82.

HALL, Stuart (2019). El triángulo funesto. Raza, etnia, nación. Madrid: Traficantes de Sueños.

HEREDIA, Iraí (2018). iTumba Negra! «Performance», memoria y experiencia danzada en los talleres de tumbe en la ciudad de Arica. Tesis de grado. Universidad de Tarapacá.

HUENCHUMIL, Paula (2020). "“Aquí no hay negros": la desconocida historia del racismo del Estado contra los afrochilenos». Interferencia, 20 de junio, [en línea]: https://interferencia. cl/articulos/aqui-no-hay-negros-la-desconocida-historia-del-racismo-del-estadocontra-los-afrochilenos (consulta: 26 de febrero de 2021).

INE (2014). Informe de Resultados Encuesta de Caracerización de la población Afrodescendiente de la Región de Arica y Parinacota. Encuesta de Caracterización Afrodescendiente (ENCAFRO), 2014.. https://centroderecursos.cultura.pe/sites/ default/files/rb/pdf/encuesta_de_caracterizacion_de_la_poblacion_afrodescendiente_ de_la_region_de_arica_y_parinacota_2013.pdf

JeLIN, Elizabeth (2012). Los trabajos de la memoria. Lima: Instituto de Estudios Peruanos.

LABELLE, Brandon (2018). Sonic agency. Sound and emergent forms of resistance. Londres: Goldsmiths Press.

LAMBORGHINI, Eva (2019). «Performances afro y movilización social: articulaciones entre arte, política y memoria en Buenos Aires». Cuicuilco Revista de Ciencias Antropológicas, Ciudad de México, 75, págs. 225-248.

LEÓN, Mariana (2017). «Los nietos de los abuelos negros...». A (re)criação da primeira comparsa de tumba carnaval. Performance, experiência e memória afrodescendente em Arica (Chile). Tesis de magíster. Niterói: Universidad Federal Fluminense.

Mbembe, Achille (2011). Necropolítica. Madrid: Melusina.

MendozA, Jorge (2007). «Suscinto recorrido por el olvido social». Polis, Ciudad de MéxiCo, 3, págs. 129-159.

MoRA, Nestor (2011). «Afro-chilenos: A produção Política nas leis e a cultural na dança em busca de reconhecimento". Revista Magistro, Duque de Caxias, 1, págs. 132-148.

PARODY, Viviana (2019). «Ciclos (globales) de política racial y procesos de corporalización pública afrodescendiente en la Argentina reciente (1976-2016)». Revista del CISEN Tramas/Maepova, Salta, 7, págs. 75-98.

RANCIÉRE, Jacques (2009). El reparto de lo sensible, estética y política. Santiago de Chile: LOM Ediciones.

RESTREPO, Eduardo (2012). Intervenciones en teoría cultural. Popayán: Editorial Universidad del Cauca. 
RIvAS, Francisco (2015). «Fenomenología política del ruido». Ixaya. Revista Universitaria de Desarrollo Social, Guadalajara, 9, págs. 75-96.

Soто, Daniel (2019). Proceso político del pueblo tribal afrodescendiente chileno, siglo XxI. Oficina de desarrollo afrodescendiente. Arica: Municipalidad de Arica.

STERn, Steve (2009). Recordando el Chile de Pinochet: En vísperas de Londres 1998. Santiago de Chile: Ediciones Universidad Diego Portales.

TAYLOR, Diana (2017). El archivo y el repertorio: el cuerpo y la memoria cultural en las Américas. Santiago de Chile: Ediciones Universidad Alberto Hurtado.

Wolf, Juan Eduardo (2019). Styling blackness in Chile: Music and dance in the African diaspora. Bloomington: Indiana University Press.

Fecha de recepción: 22 de agosto de 2020

Fecha de aceptación: 5 de marzo de 2021

Fecha de publicación: 22 de diciembre de 2021 